Genij Ortopedii. 2021. Vol. 27, no. 5. P. 508-513.

Original article

https://doi.org/10.18019/1028-4427-2021-27-5-508-513

\title{
Rationale for the use of the original classification of posttraumatic acetabular deformities in primary total hip replacement
}

\section{A.V. Tsybin, V.V. Lubchak ${ }^{\bowtie}$, V.S. Sivkov, V.A. Shilnikov, R.V. Malygin, M.I. Shubnyakov}

Vreden National Medical Research Center of Traumatology and Orthopedics, Saint Petersburg, Russian Federation

Corresponding author: Viacheslav V. Lubchak, drogbadider@mail.ru, https://orcid.org/0000-0001-7343-4529

Abstract

Introduction Analysis of publications on primary hip replacement shows lower survival rates in patients with acetabular injuries. With the lack of a unified system for assessing post-traumatic acetabular deformities, authors tend to use the available classifications of acute pelvic trauma (AO/ ASIF, Young \& Burgess, Tile, etc.) and acetabular osteolysis (AAOS, DGOT, Gross and Saleh, Paprosky), which we think can be inappropriate with the classifying systems meant for different patterns of acetabular deficiency. Material and methods CT scans of 117 patients with posttraumatic acetabular deformities were reviewed prior to total hip replacement (THR) performed for posttraumatic grade III coxarthrosis. The displacement of acetabular walls was determined with the measurements tabulated and analyzed. Results An original "ASPID" classification of post-traumatic deformities based on the findings obtained was offered with use of three assessment criteria: localization of the deformity, extent of displacement and the integrity of the pelvic ring. The ASPID classification can be used for the localization of the deformity with anterior (A), superior (S), posterior (P) and inner acetabular walls (I) to be identified. Measurements of displacement ranging 0-5 mm suggests grade 0 displacement; 6-15 $\mathrm{mm}$, grade 1 displacement and greater than $15 \mathrm{~mm}$, grade 2 displacement. The integrity of the pelvic ring evaluated from the involvement side as D0 suggests maintained pelvic integrity and D1, broken pelvic integrity. An acetabular hardware would be marked with 'H'. Conclusion ASPID classification is easy to use and has shown to be practical for planning of primary THR after acetabular fracture.

Keywords: acetabulum, arthroplasty, post-traumatic deformity, classification

For citation: Tsybin A.V., Lubchak V.V., Sivkov V.S., Shilnikov V.A., Malygin R.V., Shubnyakov M.I. Rationale for the use of the original classification of posttraumatic acetabular deformities in primary total hip replacement. Genij Ortopedii, 2021, vol. 27, no 5, pp. 508-513. https://doi. org/10.18019/1028-4427-2021-27-5-508-513

\section{INTRODUCTION}

Total hip artheroplasty (THA) is a highly effective surgical treatment for patients with diseases, injuries and posttraumatic conditions of the hip joint that allows to relieve pain within a relatively short time, restore joint function and improve the quality of life. Since 1960 THA surgical technique and implant designs have been modified and provided good long-term treatment outcomes [1]. More than one million primary THA are per-formed annually in the world [2]. There were 438,000 THAs performed in the United States alone in 2010 [3]. The N.I. Priorov CITO reported 72,270 THA procedures performed in Russia in 2018 [4]. V. Pilz et al. (2018) reported approximately 213,000 patients undergoing primary THAs in 2010 in Germany, which increased by $9 \%$ to 232,000 patients in the year 2016 (283 per 100,000). The annual number of hip replacements is forecast to grow to 288,000 by 2040 [5]. The Australian Joint Replacement Registry (2018) reported 38,379 primary THAs performed in 2012 that increased by $12 \%$ in 2018 and amounted to 42,972 hip procedures [6]. Thus, the percentage of THAs is increasing annually worldwide.

With more than fifty years of experience in modern THA, the indications for the surgical procedure have been identified and long-term results documented in the annual reports of the national joint replacement regis-tries of various countries have shown the high effectiveness of the treatment. THA is mainly indicated to treat deforming osteoarthritis of different etiologies (including idiopathic condition resulting from dysplasia, post-traumatic), femoral neck fractures, avascular necrosis of the femoral head, rheumatoid polyarthritis and pa-thology associated with oncological involvement of the hip joint. Although indications for primary THA with minor variations are described in many reports including joint replacement registries posttraumatic coxarthrosis and acetabular deformities are not identified or referred to the group of "other causes" [6].

Analysis of publications reporting results of primary THA indicates to poorer survival of implants in pa-tients with acetabular injuries. R. Stibolt et al. (2018) reported a relatively high complication rate after primary THA in patients with acetabular fractures [7]. Z. Morison et al. (2016) reported the 10-year survivorship after THA being lower in patients with a previous acetabular fracture than in the matched cohort $(70 \%$ versus $90 \%, 95 \% \mathrm{CI}$; $\mathrm{p}<$ 0.001 ) [8]. S. Khurana et al. (2015) reported similar scenario with $12.5 \%$ of posttrauma patients requiring revision a mean of 3.5 years after initial arthroplasty [9]. J. Stibolt et al. (2018) screened1830 studies after conducting a systematic review of 1,830 publications and reported $83.74 \%$ survival rate of THA in patients 
with posttraumatic coxarthrosis at 10-year follow-up that was also lower in comparison with the results of primary THA performed for other pathologies [7]. K. Hamlin et al. (2017) suggested in the systematic review that evidence based on the results of primary THA was scarce in patients with acetabular fractures due to the small subgroup of patients (about $10 \%$ ), and further work in the field was needed to improve the results [10]. Thus, a lower survival rate of implants was reported in patients with posttraumatic deformities of the acetabulum after primary THA.

The Russian and foreign literature review on primary THA indicates to the absence of a generally accepted classifying system for posttraumatic acetabular deformities discouraging the analysis of the results of primary THA in this cohort of patients and a systematic approach to the choice of surgical strategy. Instead, the au-thors report use of the existing classifications offered for acute pelvic injury (classifications of R. Judet \& E. Letournel, M. Tile, J. Young \& A. Burgess, etc.) and acetabular osteolysis (classifications of Paprosky, Gross, Saleh, etc.) [11]. In our opinion this use cannot be considered appropriate since the above classifying systems are extremely specific and were originally developed for different acetabular condition. There are AO/ASIF classifications of acute acetabular injury [12], classifications offered by J. W. Young \& A. R. Burgess [13], M. Tile [14] that are normally used for collecting and analyzing the results of THA in patients with posttraumatic deformities of the acetabulum. The classifying system, the AO classification, in particular, used for pelvic injuries are practical in describing the nature of the injury in greater details, and the algorithm for choosing the type of surgical treatment developed by the $\mathrm{AO}$ association is a generally recognized standard of treatment for these patients. However, attempts to use classifications of acute pelvic injuries for posttraumatic changes in the acetabulum during primary THA cannot identify all the manifestations that would be helpful in the choice of options (bone grafting, augments, cages, individually designed implants) for the successful im-plantation of the acetabular component and should not be used during primary THA because of posttraumatic acetabular changes.

Some authors tend to use classifications of retroacetabular osteolysis developed for revision THA, such as AAOS [15], DGOT [16], A. E. Gross and K.J. Saleh [17], W.G. Paprosky [18]. The classifications devel-oped for the analysis of retroacetabular osteolysis are evaluation systems primarily offered for revision THA and cannot provide information of the bone quality in posttraumatic acetabular deformities. Thus, the classifi-cations presented for acute acetabular injury and for retroacetabular osteolysis during revision THA are spe-cific and have limited use. They cannot be applied for a systematic assessment of the acetabulum in posttrau-matic deformities in terms of the bone quality to allow implantation of the acetabular component during pri-mary THA.

The purpose of the study was to substantiate and develop an original classification of posttraumatic acetabular deformities for primary total hip replacement.

\section{MATERIAL AND METHODS}

There were total 1,157 primary THA surgeries performed for posttraumatic grade 3 coxarthrosis between 2013 and 2018 at the Vreden National Medical Research Center of Traumatology and Orthopedics reported to the Arthroplasty Registry. Posttraumatic deformaties of the acetabular walls were reported in 313 medical charts $(27 \%)$. Of these, computer tomography of the hip joint was preoperatively performed for 117 patients. Overall, 117 cases with posttraumatic deformaties of the acetabular walls treated with primary THAs were reviewed based on the inclusion criteria. There were 80 male and 37 female patients whose age ranged from 43 to 76 years with the mean of $59 \pm 7$ years. The integrity of the pelvic ring was impaired in 9 cases $(8 \%)$.

\section{Methods of investigations}

Multiplanar image reconstructions were performed in three mutually perpendicular planes with additional control of the initial pelvic position using 3D reconstructions to measure the degree of displacement on axial CT sections. The displacement of acetabular fragments (walls) was measured between two parallel planes (lines) passing tangentially to the most distant points of the deformity formed with displaced bone. Major sur-gical landmarks of the acetabular anterior (A), superior $(\mathrm{S})$, posterior $(\mathrm{P})$ and internal (I) walls were used to describe the localization of deformities in THA and abbreviated as ASPID with D standing for pelvic discon-tinuity. The measurements were tabulated with reference number, the patient's full name, the number of the medical history and columns indicating the landmarks taken as the basis of the work, then the values ex-pressed in millimeters were analyzed for each parameter and histograms constructed. 


\section{RESULTS}

Based on the table compiled during analysis of CT scans of patients with posttraumatic acetabular deformi-ties measurements ofacetabular displacement in $\mathrm{mm}$ were reviewed separately for each wall. The number of cases with a 5-6 $\mathrm{mm}$ displacement of acetabular walls was significantly less than those with a displacement of 0 to 4 and greater than $6 \mathrm{~mm}$. Another cohort of patients with a wall displacement of greater than $15 \mathrm{~mm}$ was also identified. So, there were three types of displacement identified for each acetabular wall: degree 0, 0-5 mm, degree 1, 6-15 $\mathrm{mm}$, degree 2, more than $15 \mathrm{~mm}$ based on the effect of displacement on the pelvic bone strength and the reliable fixation of the acetabular component. The original classification is shown in Figure 1.
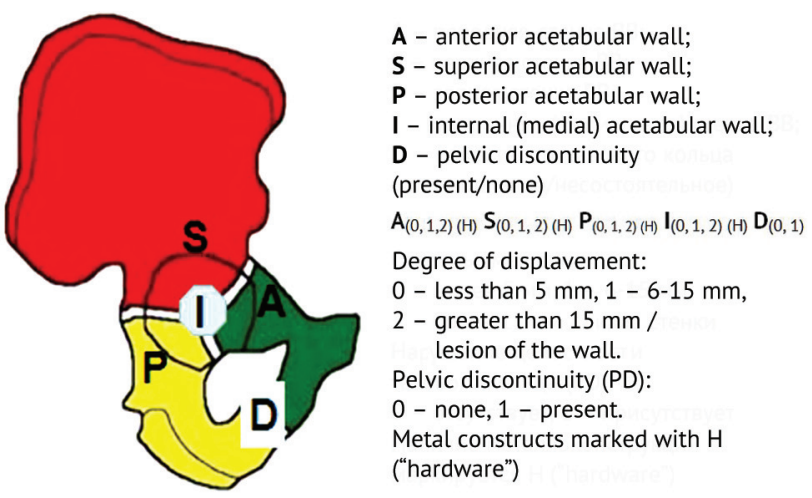

Fig. 1 ASPID classification of posttraumatic acetabular deformities

The use of the ASPID classification involved identification of the deformity localization as anterior, A, su-perior, S, posterior, P and internal, I walls ranging it from $0-5 \mathrm{~mm}$ (degree f displacement rated as 0), 6-15 $\mathrm{mm}$ (degree of displacement rated as 1) and greater than $15 \mathrm{~mm}$ (degree of displacement rated as 2) and clas-sifying the integrity of the pelvic ring from the side of the involved acetabulum as
D0 (preserved integrity of the pelvic ring) and D1 (impaired integrity of the pelvic ring). Hardware was marked with $\mathrm{H}$.

Clinical instance A 62-year-old patient $\mathrm{T}$. underwent THA of the right joint for posttraumatic grade III coxarthrosis (Fig. 2).

Medical records of 2017 showed an acetabular fracture and traumatic dislocation of the right hip resulting froma traffic accident. The fracture was plated in January 2018 with the hip dislocation relapsed in the post-operative period that was reduced and fixed with external fixation device. Radiographic and CT examination of the right hip joint was performed for the patient on admission to the hospital of the Vreden Medical Center. Prototyping and 3D modeling of the acetabulum were performed preoperatively due to severity of the injury and pronounced posttraumatic changes in the acetabular anatomy (Fig. 3).

The investigations showed absent superior and posterior acetabular walls, a reconstruction plate and screws that fixed posterior bone fragments. According to the original ASPID classification the formula of the acetab-ular deformity of the patient appeared as A0S2P2HIOD0, and was interpreted as displacement of the superior and posterior acetabular walls of greater than $15 \mathrm{~mm}$ or osteolysis (absence of the wall), presence of metal construct in the posterior wall with maintained integrity of the pelvic ring. Preoperative prototyping was prac-tical for measuring the acetabular component $(56 \mathrm{~mm})$, position and size of the highly porous replacement block $(54 \times 20 \mathrm{~mm})$. The replacement block was used because of unavailable structural autograft to address complete lysis of the head due to posttraumatic avascular necrosis. Accurate preoperative planning facilitated arthroplasty with hybrid fixation of the components, 90-minute operating time and blood loss of $250 \mathrm{~mL}$ (Fig. 4).
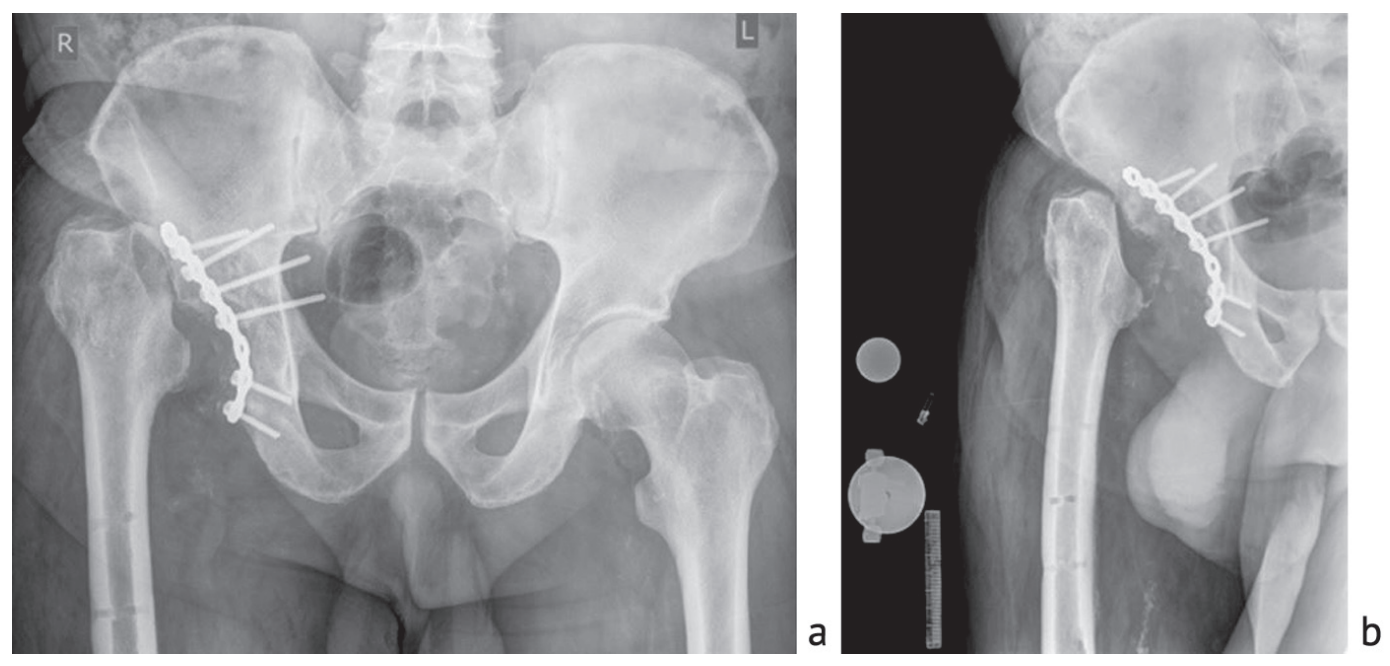

Fig. 2 Preoperative radiographs (a) of the pelvis; (b) lateral view of the right hip joint 


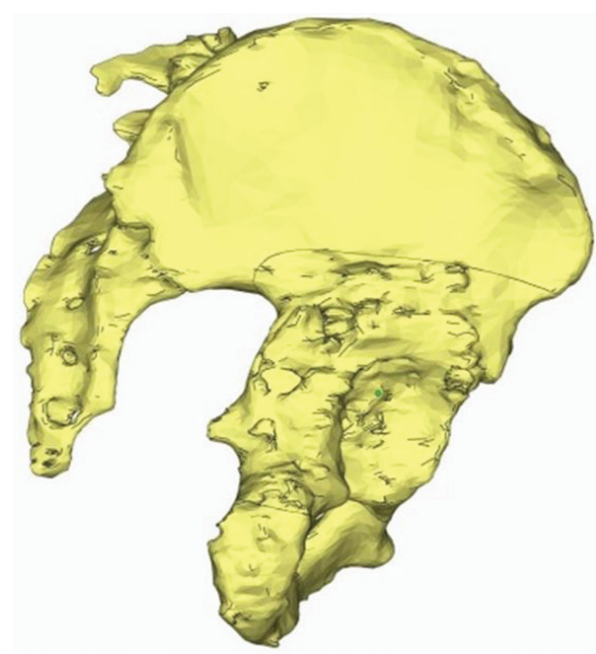

Fig. 3 The result of prototyping of the right acetabulum, 3D reconstruction at different angles

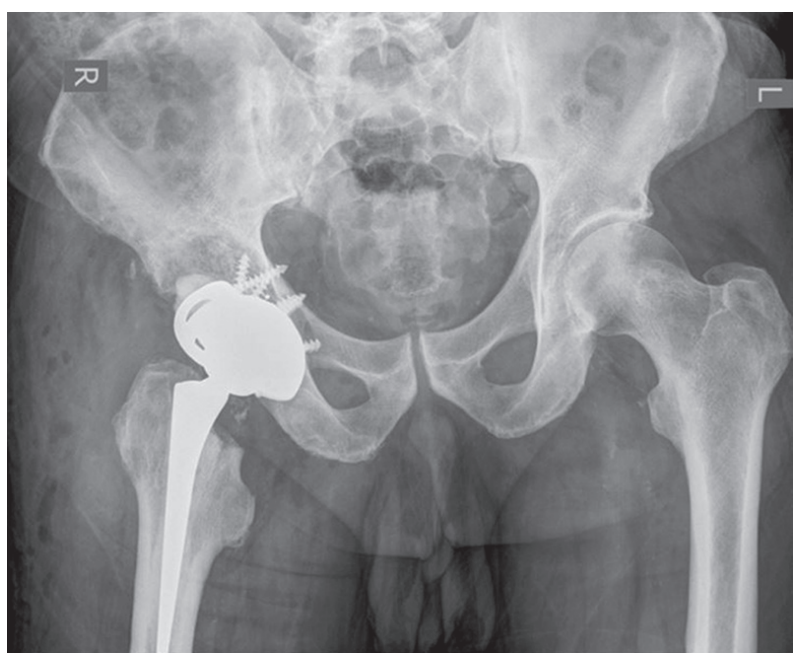

Fig. 4 Plain radiograph of pelvis of patient T. showing THA of the right hip joint

\section{DISCUSSION}

An original classification of posttraumatic coxarthrosis was proposed at the R.R. Vreden Russian Research Institute in 2011 and used the radiological landmarks of the iliac crest line, the iliac-sciatic line, the roof of the acetabulum, the anterior edge of the acetabulum, the posterior edge of the acetabulum $[19,20]$. The authors identified three major types of acetabular changes in the classifying system that were subdivided into groups depending on the displacement of the femoral head:

type 1: the femoral head is normally centered, the sphericity of the acetabulum preserved, there are minor changes in the posterior wall, the reference iliac crest and iliac-sciatic lines;

type 2: the femoral head is subluxated, there is a significantly impaired sphericity of the acetabulum and significant defects in the posterior acetabular wall. Considering the degree of displacement of the femoral head seen on computed tomography scans the group is divided into $2 \mathrm{a}, 2 \mathrm{~b}$ and $2 \mathrm{~b}$ subgroups:

$2 \mathrm{a}$, displacement of the femoral head up to $25 \%$ of the diameter;

$2 \mathrm{~b}$, displacement of the femoral head of $25 \%$ to $50 \%$ of the diameter;

$2 \mathrm{c}$, displacement of the femoral head greater than $50 \%$ of the diameter;

type 3: completely impaired anatomy of the hip joint with deformed medial wall and /or the femoral head located behind the Koehler line, defects in both walls, distorted reference lines and unstable pelvic ring.

The classification offered was actually the first attempt to systematize posttraumatic injuries to the ace-tabulum allowing generalization and choice of strategy in primary THA and was recommended by the Minis-try of Health of Russia as clinical guidelines of 2016. However, it has not been widely used since then as seen from publications on the problem. The grading system was difficult to be used for posttraumatic cases of avascular necrosis of the femoral head and could not be applied for the above clinical example.

A.Yu. Milyukov (2012) developed an original classification of acetabular injuries [21]. He first offered to identify two large groups of patients with (A) isolated injuries to the acetabulum and (B) injuries to the ace-tabulum combined with an injury to the pelvic ring. Then he suggested localize the injury at the site of (I) pu-bic, (II) iliac and (III) ischial bones. And, third, the author described the direction of migrated femoral head (Table 1).

Although the classifications presented have a scientific value and have contributed to the development of modern orthopaedics initiating a systematic approach to patients with posttraumatic deformities of the acetab-ulum the systems have not been widely used. One of disadvantages of the grading systems is that they tend to "bind" a clinical scenario to the position of the femoral head that can be absent in some cases as seen from the above clinical case. Thus, the known classifications cannot be used for primary THA with posttraumatic de-formities of the acetabulum, as demonstrated by the clinical instance presented. In our opinion, the grading system offered can be easily reproducible and universal with no language limitations allowing accurate de-scription of the acetabulum with the use of a letter-digital code to form a database for further statistical pro-cessing. 
Injuries to the acetabulum as classified by A.Yu. Milyukov

\begin{tabular}{|l|l|l|}
\hline Group A, isolated injuries to the acetabulum & I & Pubic bone \\
\cline { 2 - 3 } Localization of acetabular injury & II & Iliac bone \\
\cline { 2 - 3 } & III & Ischial bone \\
\cline { 2 - 3 } Type of injury and dislocation of the femoral head & IV & Pubic, iliac, ischial bones \\
\hline \multirow{5}{*}{ Sar 0 } & Normal alignment \\
\cline { 2 - 3 } & Sar I & Extended to iliac bone \\
\cline { 2 - 3 } & Sar II & Extended to ischial bone \\
\cline { 2 - 3 } & Sar III & Extended to pubic bone \\
\cline { 2 - 3 } & Sar IV & Extended to the acetabular roof or the pelvis \\
\cline { 2 - 3 } & Sar F & Broken femoral head \\
\hline Group B, combined injuries to the acetabulum and to the pelvic ring & \\
\hline
\end{tabular}

THA procedure performed in posttraumatic changes of the acetabulum is often a complicated surgical in-tervention due to the difficulties of implantation of the acetabular component. The analysis of publications on the problem indicates the absence of a unified system for assessing the acetabulum with posttraumatic chang-es, and the data presented in the literature are scattered and not liable to any generalization and a systematic approach. The grading system offered and the letter-digital code presented for the acetabular deformity allow accurate description of the changes in the supporting structures, identification of the hardware and integrity of the pelvic ring providing detailed information for preoperative planning. On the one hand, the grading system allows you to customize the data for thorough planning of the primary THA, on the other hand, a letter-digital formula facilitates collection and texturing data for statistical processing that can be a key factor for the algo-rithm to be used for surgical strategy. The classification is currently used to develop a database and analyze outcomes of primary THA in patients with posttraumatic acetabular deformities.The letter-digital code facili-tates the formation of an extensive database with available description of acetabular walls, hardware and integrity of the pelvic ring identified preoperatively to allow a comprehensive analysis of factors that may cause aseptic loosening of the acetabular component.

The basic principles of the algorithm for surgical strategy depending on the localization and degree of dis-placement of the acetabular walls should involve assessment of the congruence of the standard hemispherical acetabular component using"press-fit" fixation and impaired acetabular anatomy. In addition to that, such an algorithm is to be based on the general principles of primary THA and include additional options like auto-grafts, screw fixation, trabecular metal blocks and tailored acetabular systems for severely distorted acetabular anatomy. The algorithm based on the above principles will be finalized and presented in greater details in subsequent publications.

\section{CONCLUSION}

1. None of the current classifications of posttraumatic coxarthrosis can provide appropriate description of the acetabulum with posttraumatic deformities for accurate preoperative planning of primary THA in this cohort of patients.
2. The ASPID classification based on CT studies and examination of 117 patients allows identification of acetabular anatomy complicated with posttraumatic deformities, is easy to use and has shown to be practical for planning of primary THA after acetabular fracture.

\section{REFERENCES}

1. Karachalios T., Komnos G., Koutalos A. Total hip arthroplasty: Survival and modes of failure. EFORT Open Rev., 2018, vol. 3, no. 5, pp. 232-239. DOI: 10.1302/2058-5241.3.170068.

2. Pivec R., Johnson A.J., Mears S.C., Mont M.A. Hip arthroplasty. Lancet, 2012, vol. 380, no. 9855, pp. 1768-1777. DOI: 10.1016/ S0140-6736(12)60607-2.

3. Singh J.A., Schleck C., Harmsen S., Lewallen D. Clinically important improvement thresholds for Harris Hip Score and its ability to predict revision risk after primary total hip arthroplasty. BMC Musculoskelet. Disord., 2016, vol. 17, pp. 256. DOI: 10.1186/s12891016-1106-8.

4. Andreeva T.M., Ogryzko E.V., Popova M.M., comp. Eskin N.A., editor. Travmatizm, ortopedicheskaia zabolevaemost, sostoianie travmatologo-ortopedicheskoi pomoshchi naseleniiu Rossii v 2018 godu: sbornik [Traumatism, orthopedic morbidity, the state of traumatological and orthopedic care for the population of Russia in 2018: collection of works]. M., TsITO im. N.N. Priorova, 2019, 166 p. (in Russian)

5. Pilz V., Hanstein T., Skripitz R. Projections of primary hip arthroplasty in Germany until 2040. Acta Orthopaedica, 2018, vol. 89, no. 3, pp. 308-313. DOI: 10.1080/17453674.2018.1446463. 
6. Stibolt R.D. Jr., Patel H.A., Huntley S.R., Lehtonen E.J., Shah A.B., Naranje S.M. Total hip arthroplasty for posttraumatic osteoarthritis following acetabular fracture: A systematic review of characteristics, outcomes, and complications. Chin. J. Traumatol., 2018, vol. 21, no. 3, pp. 176-181. DOI: 10.1016/j.cjtee.2018.02.004.

7. Morison Z., Moojen D.J., Nauth A., Hall J., McKee M.D., Waddell J.P., Schemitsch E.H. Total hip arthroplasty after acetabular fracture is associated with lower survivorship and more complications. Clin. Orthop. Relat. Res., 2016, vol. 474, no. 2, pp. $392-398$. DOI: 10.1007/s11999-015-4509-1.

8. Khurana S., Nobel T.B., Merkow J.S., Walsh M., Egol K.A. Total hip arthroplasty for posttraumatic osteoarthritis of the hip fares worse than THA for primary osteoarthritis. Am. J. Orthop. (Belle Mead NJ), 2015, vol. 44, no. 7, pp. 321-325.

9. Hamlin K., Lazaraviciute G., Koullouros M., Chouari T., Stevenson I.M., Hamilton S.W. Should total hip arthroplasty be performed acutely in the treatment of acetabular fractures in elderly or used as a salvage procedure only? Indian J. Orthop., 2017, vol. 51, no. 4, pp. 421-433. DOI: 10.4103/ortho.IJOrtho_138_16.

10.Pronskikh A.A., Kharitonov K.N., Kuzin V.Iu., Efimenko M.V., Golenkov O.I., Pavlov V.V. Endoprotezirovanie tazobedrennogo sustava u patsientov s obshirnymi posttravmaticheskimi defektami vertluzhnoi vpadiny sovremennye problemy nauki i obrazovaniia [Arthoroplasty of the hip in patients with extensive posttraumatic defects of the acetabulum]. Sovremennye Problemy Nauki $i$ Obrazovaniia, 2019, no. 5. (in Russian) Available at: http://www.science-education.ru/ru/article/view?id=29253 (accessed 08.03.2021).

11.Meinberg E.G., Agel J., Roberts C.S., Karam M.D., Kellam J.F. Fracture and dislocation classification compendium-2018. J. Orthop. Trauma, 2018, vol. 32, no. Suppl. 1, pp. S1-S170. DOI: 10.1097/BOT.0000000000001063.

12.Burgess A.R., Eastridge B.J., Young J.W., Ellison T.S., Ellison P.S. Jr., Poka A., Bathon G.H., Brumback R.J. Pelvic ring disruptions: effective classification system and treatment protocols. J. Trauma, 1990, vol. 30, no. 7, pp. 848-856.

13.Tile M. Pelvic ring fractures: should they be fixed? J. Bone Joint Surg. Br., 1988, vol. 70, no. 1, pp. 1-12. DOI: 10.1302/0301-620X.7 0B1.3276697.

14.D'Antonio J.A., Capello W.N., Borden L.S., Bargar W.L., Bierbaum B.F., Boettcher W.G., Steinberg M.E., Stulberg S.D., Wedge J.H. Classification and management of acetabular abnormalities in total hip arthroplasty. Clin. Orthop. Relat. Res., 1989, no. 243, pp.126137.

15.Bettin D., Katthagen B.D. Die DGOT-Klassifikation von Knochendefekten bei Hüft-Totalendoprothesen-Revisionsoperationen [The German Society of orthopedics and Traumatology classification of bone defects in total hip endoprostheses revision operations]. Z. Orthop. Ihre. Grenzgeb., 1997, vol. 135, no. 4, pp. 281-284. (in German) DOI: 10.1055/s-2008-1039389.

16.Saleh K.J., Holtzman J., Gafnia Saleh L., Jaroszynski G., Wong P., Woodgate I., Davis A., Gross A.E. Development, test reliability and validation of a classification for revision hip arthroplasty. J. Orthop. Res., 2001, vol. 19, no. 1, pp. 50-56. DOI: 10.1016/S07360266(00)00021-8.

17.Paprosky W.G., Perona P.G., Lawrence J.M. Acetabular defect classification and surgical reconstruction in revision arthroplasty. A 6-year follow-up evaluation. J. Arthroplasty, 1994, vol. 9, no. 1, pp. 33-44. DOI: 10.1016/0883-5403(94)90135-x.

18.Chiladze I.T. Totalnoe endoprotezirovanie tazobedrennogo sustava pri posledstviiakh perelomov vertluzhnoi vpadiny. Avtoref. diss. kand. med. nauk [Total arthroplasty of the hip for the consequences of acetabular fractures. Cand. med. sci. diss. abstr.]. SPb., 2011, 27 p. (in Russian)

19.Tikhilov R.M., Shubniakov I.I., Chiladze I.T., Pliev D.G., Shorustamov M.T., Artiukh V.A., Ambrosenkov A.V., Blizniukov V.V., Miasoedov A.A. Vybor sposoba implantatsii vertluzhnogo komponenta na osnove rabochei klassifikatsii posledstvii perelomov vertluzhnoi vpadiny [The choice of the technique of implantation of the acetabular component based on the working classification of the consequences of acetabular fractures].Travmatologiia i Ortopediia Rossii, 2011, no. 2 (60), pp. 37-43. (in Russian)

20.Miliukov A.Iu. Klassifikatsiia povrezhdenii vertluzhnoi vpadiny [Classification of acetabular injuries]. Meditsina $i$ Obrazovanie $v$ Sibiri, 2012, no. 2, pp. 53-54. (in Russian)

The article was submitted 17.03.2021; approved after reviewing 19.04.2021; accepted for publication 23.08.2021.

\section{Information about the authors:}

1. Alexandr V. Tsybin - Candidate of Medical Sciences, alex_tsybin@mail.ru;

2. Vyacheslav V. Lubchak - M.D., drogbadider@mail.ru, https://orcid.org/0000-0001-7343-4529;

3. Vyacheslav S. Sivkov - Candidate of Medical Sciences, drogbadider@mail.ru;

4. Viktor A. Shilnikov - Doctor of Medical Sciences, med-03@yandex.ru;

5. Roman V. Malygin - Candidate of Medical Sciences, malyginrv@yandex.ru;

6. Maksim I. Shubnyakov, M.D., maximtravmatolog@gmail.ru. 